Artículo Original

\title{
Ébola en zonas rurales: lecciones aprendidas en la epidemia de África Occidental y últimas novedades
}

\author{
Mario Pérez-Butragueño ${ }^{1, *}$ y Belén Comeche ${ }^{2}$ \\ 1 Médicos del Mundo. Servicio de Pediatría. Hospital Universitario Infanta Leonor. Madrid; ORCID id: \\ https://orcid.org/0000-0002-8850-2878 \\ 2 Médicos del Mundo. Unidad de Medicina Tropical. Hospital Universitario Ramón y Cajal. Madrid; ORCID \\ id: https://orcid.org/0000-0001-5760-8824 \\ * Autor correspondencia: marioperezb@hotmail.com
}

Belén Comeche y Mario Pérez-Butragueño pertenecen actualmente al Grupo de Intervención Rápida en Acción Humanitaria (GIRAH) y al Grupo estatal de Palestina de Médicos del Mundo. Son profesores del Máster Universitario de Acción Humanitaria Sanitaria (MUAHS). Ambos participaron en la Emergencia del Ébola de Sierra Leona en 2015 con Médicos del Mundo en el distrito de Koinadugu.

DOI: https://doi.org/10.37536/RIECS.2020.5.S1.180

Recibido: 24/01/2020; Aceptado: 05/02/2020; Publicado: 14/02/2020

Resumen: Un brote de Ébola en un área rural (con pocos pacientes dispersos en una zona aislada o remota) presenta ciertas peculiaridades que afectan a su manejo y lo diferencian del que se realiza en zonas urbanas (con mayor número de pacientes, más accesibles y con gran densidad poblacional). En una zona rural se deben diseñar estrategias para que los 6 pilares fundamentales para la erradicación del brote sean llevados a cabo de forma efectiva hasta en las zona más remotas y aisladas. Hay que sacar a los casos sospechosos fuera de los centros médicos habituales y crear centros de aislamiento diseñados de forma que cumplan escrupulosamente las normas de seguridad. El manejo de los pacientes debe hacerse en dichos centros de aislamiento donde se les puedan tomar muestras, aislar y tratar hasta que se confirma o se descarta el diagnóstico En el primer caso serán trasladados a un Centro de tratamiento de Ébola para su manejo. Las diferentes estrategias de vacunación suponen un nuevo campo muy interesante para evitar la diseminación del brote en zonas aisladas. Nuevos dispositivos como el CUBE también suponen un gran avance para el manejo de pacientes en zonas rurales.

Palabras Clave: Ébola, Áreas rurales, Manejo.

Abstract: An Ébola outbreak in a rural area (with few patients dispersed in an isolated or remote zone) presents certain peculiarities that affect its management and make it different from an Ébola outbreak in urban areas (with a greater number of patients and with high population density). In a rural area is necessary to design strategies so that the 6 fundamental pillars for the eradication of the outbreak are carried out effectively, even in the most remote and isolated areas. Suspicious cases must be taken outside of regular medical centers and isolated at holding centers that must be built in a manner that scrupulously complies with safety regulations. The management of suspicious cases (isolation, sampling and treatment) should be done in these holding centers until the diagnosis is confirmed or discarded. In the first case, they will be transferred to an Ébola Treatment Center for management. The different vaccination strategies represent a very interesting new field to prevent the spread of the outbreak in specific areas. New devices such as CUBE also represent a great advance for the management of patients in rural areas.

Key words: Ébola, Rural settings, Management. 


\section{Introducción}

La epidemia de Ébola en África occidental supuso un desafío a nivel mundial sin precedentes. La declaración oficial del inicio de la epidemia en Guinea ocurrió a finales de marzo de 2014. Según las cifras oficiales en los siguientes dos años hasta el fin de la epidemia en 2016, hubo 28.616 personas infectadas; 11.310 fallecidas y tres sistemas de salud quedaron aún más colapsados que al principio de la epidemia [1,2].

La intervención de Médicos del Mundo (MDM) en Sierra Leona incluyó la apertura de un centro de tratamiento de Ébola (CTE) en el distrito de Moyamba y la gestión de 3 centros de aislamiento o Community Care Centers (CCC) en zonas rurales del distrito de Koinadugu [1].

Visto con perspectiva muchas han sido las lecciones aprendidas durante la epidemia [3] aunque aún queda mucho por mejorar como nos demuestra el brote actual en República Democrática del Congo (RDC). Una de estas lecciones ha sido tener en cuenta las diferencias en el manejo de la epidemia en zonas rurales con población dispersa y con pocos casos con respecto a las zonas urbanas con gran densidad poblacional y gran número de casos. Este artículo pretende revisar el manejo del Ébola en zonas rurales y mencionar brevemente las novedades aparecidas en la epidemia actual en RDC.

\section{Planificación y coordinación: Los seis pilares fundamentales}

El manejo de un brote de Ébola en una zona rural supone una importante labor de coordinación y planificación. La estrategia para acabar con un brote de Ébola se basa en seis pilares fundamentales (Tabla I) [4].

Tabla I Seis pilares de la lucha contra un brote de Ébola. Elaboración propia

Cuidado y aislamiento de pacientes

Seguimiento y aislamiento de contactos

Sensibilizar a la comunidad sobre la enfermedad, cómo prevenirla y dónde buscar atención

Realización de entierros seguros

Detección proactiva de nuevos casos

Apoyo a las estructuras de salud existentes

Sin el abordaje efectivo de todos y cada uno de ellos es muy difícil conseguir acabar con el brote y en una zona rural esto puede ser complicado.

La sensibilización de la comunidad va a ser clave a la hora de conseguir el apoyo de la población en los aislamientos de contactos, entierros seguros y detección de nuevos casos. En las tareas de sensibilización hay que tener siempre una perspectiva antropológica que tenga en cuenta costumbres y rituales locales y tanto para la sensibilización como para la búsqueda activa de casos hay que elaborar una estrategia que llegue a las zonas más remotas del terreno. En Koinadugu, por ejemplo, MDM organizó visitas de sensibilización a los poblados más aislados con promotores de salud que se desplazaban en motocicletas.

Los aislamientos de los contactos se realizan generalmente en las propias casas de las familias de los pacientes y a dichos contactos hay que facilitarles la alimentación e higiene durante las tres semanas que dura el aislamiento. Además, durante ese periodo, las familias deben abandonar el cuidado de sus huertos o ganado, en el caso de que un nuevo caso se declare en el domicilio hay que comenzar de nuevo con el aislamiento desde cero. Así, en Koinadugu se organizaron equipos que se dedicaban a visitar periódicamente a los contactos aislados para reforzar la importancia del aislamiento, proveer de suministros y comprobar que no habían aparecido nuevos casos.

En el terreno es frecuente que diferentes organizaciones se encarguen de cada uno de los pilares y esto implica un gran esfuerzo de coordinación. Es importante clarificar cuales son las funciones y responsabilidades de cada una, así como las formas de comunicarse y coordinarse entre ellas. En Koinadugu había reuniones diarias de coordinación a las que asistían todos lo agentes implicados 
(autoridades locales, ejército, ministerio de sanidad, Organización Mundial de la salud (OMS) y las diferentes ONGs implicadas).

También es fundamental planificar bien el flujo de los casos y dónde son atendidos. En Koinadugu al declararse el brote la premura de tiempo y escasez de medios inicial llevaron a las autoridades a que se atendieran casos en el Hospital de Kabala (capital del distrito) y en la escuela de Kumala (zona rural más afectada) (Figura 1). El resultado fue que, por una parte, el hospital de la capital se vació de pacientes temerosos de ser atendidos de sus dolencias en un centro con Ébola donde ellos podrían contagiarse y, por otra parte, la escuela de Kumala no tenía la estructura óptima para albergar un CCC a la vez que se estigmatizaba a un edificio clave en el futuro de la localidad. Posteriormente MDM junto con OXFAM y las autoridades locales elaboraron un plan integral de manejo del Ébola en la zona:

- Se creó un triage a la entrada del Hospital de Kabala. Los pacientes sospechosos de Ébola eran detectados y derivados fuera del hospital a un CCC de nueva construcción en Kasumpe, una población muy cercana. Así los pacientes quirúrgicos o con otras patologías volvieron a acudir sin miedo al hospital. El CCC de Kasumpe se diseñó y construyó partiendo de cero, siguiendo las normas de seguridad necesarias para centros de aislamiento de Ébola (Figura 1).

- Se creó un CCC nuevo en Kumala fuera de la escuela que cumplía todas las normas de seguridad. Cuando se pudo se trasladó la atención de pacientes sospechosos de Ébola a este nuevo centro, liberando la escuela que volvió a ser centro educativo.
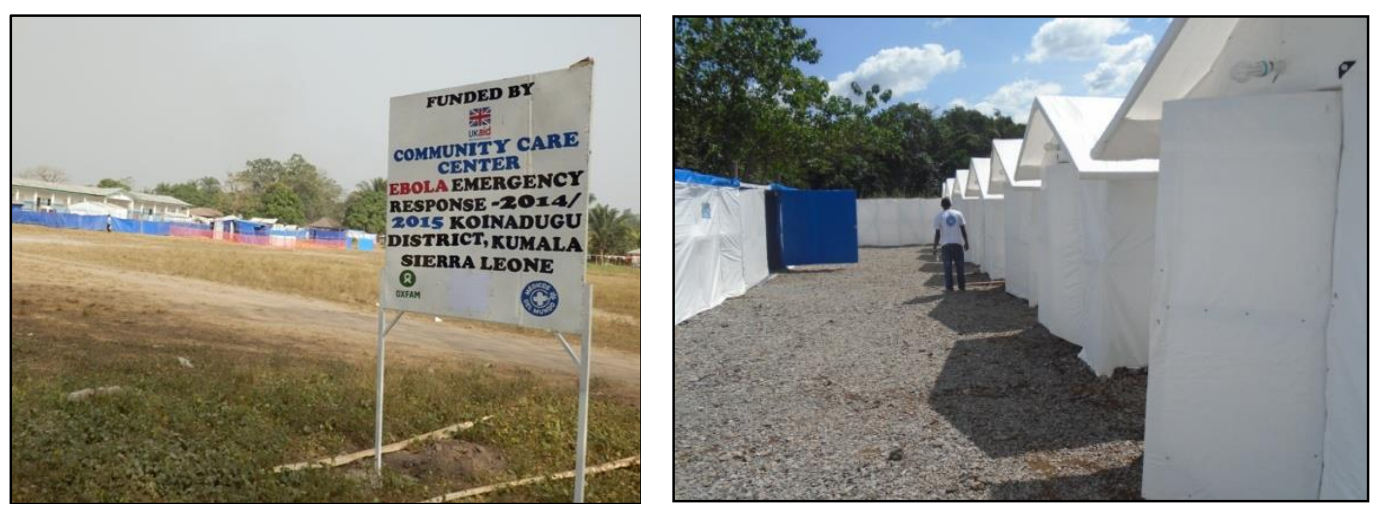

Figura 1 Izquierda: CCC en la escuela de Kumala. Derecha: obra de construcción del Centro de Kasumpe cerca de la capital Kabala.

Por tanto, en la planificación es clave sacar los casos sospechosos fuera de los centros médicos habituales y crear centros de aislamiento diseñados de forma que cumplan escrupulosamente las normas de seguridad.

\section{Manejo de los pacientes: Community Care Centre}

En torno a septiembre de 2014 la OMS, junto con los Ministerios de Sanidad de los países implicados, indicaron la creación de CCCs para el cuidado de los enfermos de Ébola en localizaciones remotas o con difícil acceso a CTEs [5]. La función de estos centros era poder manejar pacientes con sospecha de Ébola hasta tener los resultados definitivos y poder ser trasladados a un CTE [6]. La denominación CCC se ha igualado en la literatura a Holding Centre, Holding Unit o Centro de aislamiento y se ha objetivado que es una buena estrategia de manejo de pacientes en los casos referidos previamente [7].

Un ejemplo lo tenemos en Kumala, localidad donde más casos hubo en Koinadugu, en la que al inicio se estableció un CCC en la antigua escuela de la población que estaba en desuso en ese momento (Figura 2). Sin embargo, la alta tasa de mortalidad y los numerosos contagios de personal sanitario, hicieron que se trasladara el CCC a la escuela en uso de la población y que la coordinación y seguridad pasara a cargo de MDM en colaboración con OXFAM (Figura 2). 

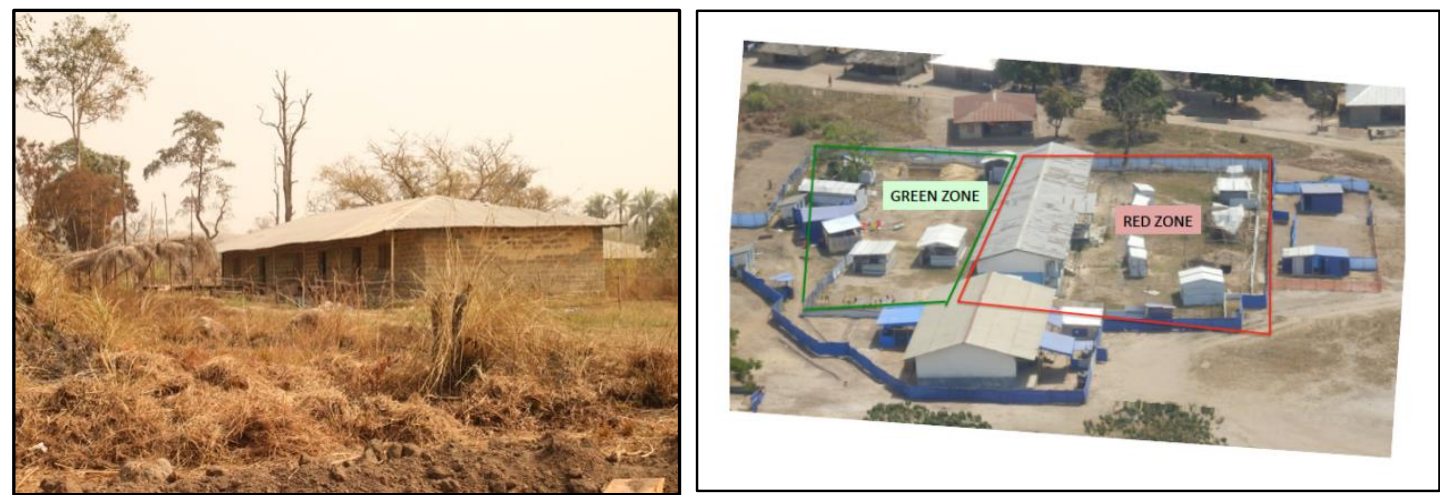

Figura 2 Izquierda: Primer CCC establecido en Kumala en la antigua escuela en desuso. Derecha: CCC en la escuela de Kumala, colaboración MDM y OXFAM. Zona roja y zona verde.

La estructura de un CCC no dista de la que tiene un ETC (pero a menor escala) ya que los pacientes son posibles enfermos de Ébola y, por tanto, se establecen las mismas medidas de aislamiento y seguridad para el personal sanitario. Consta de un área verde (bajo riesgo) en donde el personal viste con medidas básicas de protección (pijama y botas de goma). Aquí se encuentra la zona de puesta del Equipo de Protección Individual (EPI) y de retirada de este y es el área en donde se realiza la desinfección de aquellas prendas que no se descartan tras un uso (guantes de goma, gafas de protección, botas de goma...). En la zona roja (alto riesgo) es donde ingresan los pacientes y que en Kumala se trataba de las aulas de la escuela. En esta zona, también se encuentra el área en donde se incineran los residuos generados.

El Centro de Aislamiento tiene una zona de triage a la entrada de la zona roja. Los pacientes sospechosos ingresan y son sometidos a una extracción de sangre para realizar una PCR de virus Ébola. La muestra se envía a un laboratorio especializado, generalmente en un ETC. En Kumala las muestras se enviaban por helicóptero o ambulancia. Mientras llegan los resultados, el paciente recibía tratamiento de soporte, cómo si se tratase de un paciente con Ébola, con antimaláricos, antibióticos de amplio espectro, antipiréticos, antieméticos y soluciones de rehidratación.

Si los resultados de la primera PCR eran positivos el paciente se trasladaba al ETC más cercano. Si los resultados eran negativos se repetía el diagnóstico y según esta segunda determinación se decidía si el paciente podía ser dado de alta (dos PCR negativas) o se trasladaba a un ETC.

\section{Novedades en la epidemia actual de República Democrática del Congo (RDC): la vacuna y "The Cube"}

Algunas medidas que se han implementado en la epidemia actual de RDC son especialmente útiles en brotes en zonas rurales. Como ejemplo tenemos las diferentes estrategias de vacunación y el nuevo dispositivo denominado CUBE.

Son varias las vacunas que se están ensayando para el Ébola. Las dos que se están utilizando en la actual epidemia del RDC son: la vacuna Ad26.ZEBOV/MVA-BN-Filo y la rVSV-ZEBOV- GP [8]. Se está realizando una estrategia de vacunación en anillo, de manera que se vacuna a aquellas personas en riesgo de adquirir la enfermedad (los contactos de casos confirmados y los contactos de contactos) comprobando la elevada eficacia de esta medida [9]. Por otro lado, para aumentar la conformidad con la vacunación permitiendo mayor seguridad y anonimato, se está realizando una vacunación de tipo "pop-up", lo cual quiere decir que se vacuna fuera de las residencias de los contactos, por ejemplo, en una escuela o un puesto de salud [10].

Una de las innovaciones más interesantes en el manejo de los pacientes con Ébola en zonas rurales es el Biosecure Emergency Care Unit (CUBE) que ha sido utilizado por primera vez en el actual brote de RDC. El CUBE es una unidad individual de aislamiento para el paciente [11, 12]. Ha sido desarrollado por The Aliance for International Medical Actions (ALIMA) junto con Securitec. El concepto es aislar al paciente en lugar de aislar al sanitario con el EPI. Consiste en una habitación (un cubo) formado por 4 paredes de plástico trasparente con diversos dispositivos para poder acceder al 
paciente y administrarle medicación. Al ser trasparente, el paciente puede interactuar con el sanitario o con su familia y se pueden monitorizar sus constantes. Varias son las ventajas (Tabla II) y entre ellas está la posibilidad de montarlo rápidamente en zonas remotas, con pocos pacientes, incluso en la puerta de su domicilio [12].

Tabla II Ventajas del CUBE frente al CTE. Elaboración propia

Contacto visual entre el paciente y sus familiares y sanitarios

El paciente se siente menos aislado

El sanitario puede realizar el 80\% de sus actividades médicas sin el EPI

Menor coste económico

Instalación rápida (90 minutos) en la zona del brote, incluso en regiones aisladas

Puede ser montado y desmontado hasta 10 veces

Modular (de 9 a $36 \mathrm{~m}^{2}$ )

Nivel 4 de bioseguridad

Aire acondicionado

\section{Conclusiones}

Un brote de Ébola en una zona rural presenta ciertas peculiaridades que afectan a su manejo. Se deben diseñar estrategias de manera que los seis pilares fundamentales para la erradicación del brote sean llevados a cabo de forma efectiva hasta en las zona más remotas y aisladas. Hay que sacar a los casos sospechosos fuera de los centros médicos habituales y crear centros de aislamiento diseñados de forma que cumplan escrupulosamente las normas de seguridad. El manejo de los pacientes debe hacerse en dichos centros de aislamiento donde se les pueda tomar muestras, aislar y tratar hasta que se confirme o se descarte el diagnóstico En el primer caso serán trasladados a un CTE para su manejo. Las diferentes estrategias de vacunación suponen un campo muy interesante para evitar la diseminación del brote en zonas aisladas. Nuevos dispositivos como el CUBE también suponen un gran avance para el manejo de pacientes en zonas rurales.

Agradecimientos: No se han recibido subvenciones para la realización de este artículo.

Contribución de los autores: B.C. redactó el punto 2 y el 3; M.P. redactó la introducción, el punto 1,3 y las conclusiones.

Conflictos de Intereses: Los autores no declaran conflicto de intereses.

\section{Abreviaturas}

Las siguientes abreviaturas son usadas en este manuscrito:

MDM: Médicos del Mundo

CTE: Centro de tratamiento de Ébola

CCC: Community Care Center

RDC: República Democrática del Congo

OMS: Organización Mundial de la Salud

EPI: Equipo de protección individual 


\section{Referencias Bibliográficas}

1. Médicos del Mundo España. Informe sobre el Ébola en Sierra Leona [Internet]. 2015. Available from: https://www.medicosdelmundo.org/actualidad-y-publicaciones/publicaciones/informe-Ébola-en-sierra-le ona

2. World Health Organization. Situation Report - Ébola Virus [Internet]. World Health Organization. 2016. Available from: http://apps.who.int/Ébola/Ébola-situation-reports\%0Ahttps://apps.who.int/iris/bitstream/handle/10665/20 8883/Ébolasitrep_10Jun2016_eng.pdf;jsessionid=F18A12FCE559B4AE97FC43CBC1907961?sequence=1

3. Spengler JR, Ervin ED, Towner JS, Rollin PE, Nichol ST. Perspectives on West Africa Ébola Virus Disease Outbreak, 2013-2016. Emerg Infect Dis. 2016;22(6):956-63.

4. Medecins sans frontieres. Ébola and Marburg [Internet]. MSF Web. 2020 [cited 2020 Jan 19]. Available from: https://www.msf.org/Ébola

5. Olu O, Cormican M, Kamara KB, Butt W. Community Care Centre (CCC) as adjunct in the management of Ébola Virus Disease (EVD) cases during outbreaks: experience from Sierra Leone. Pan Afr Med J. 2015;22(November 2014):14.

6. Logan G, Vora NM, Nyensuah TG, Gasasira A, Mott J, Walke H, et al. Establishment of a community care center for isolation and management of Ébola patients - Bomi County, Liberia, October 2014. Morb Mortal Wkly Rep. 2014;63(44):1010-2.

7. Arkell P, Youkee D, Brown CS, Kamara A, Kamara TB, Johnson O, et al. Quantifying the risk of nosocomial infection within Ébola Holding Units: a retrospective cohort study of negative patients discharged from five Ébola Holding Units in Western Area, Sierra Leone. Trop Med Int Heal. 2017;22(1):32-40.

8. Inungu J, Iheduru-Anderson K, J Odio O. Recurrent Ébolavirus disease in the Democratic Republic of Congo: update and challenges. AIMS Public Heal. 2019;6(4):502-13.

9. World Health Organization (WHO). Preliminary results on the efficacy of rVSV-ZEBOV-GP Ébola vaccine using the ring vaccination strategy in the control of an Ébola outbreak in the Democratic Republic of the Congo: an example of integration of research into epidemic response. Vol. 175. 2019.

10. Wells CR, Pandey A, Parpia AS, Fitzpatrick MC, Meyers LA, Singer BH, et al. Ébola vaccination in the Democratic Republic of the Congo. Proc Natl Acad Sci U S A. 2019;116(20):10178-83.

11. Devi S. FRONTLINE: a new treatment facility for Ébola virus disease. Lancet (London, England). 2018;392(10163):2428.

12. ALIMA. CUBE: a new innovation in the treatment of Ébola and Marburg [Internet]. Brochure. 2020 [cited 2020 Jan 20]. Available from: https://www.alima-ngo.org/uploads/831a19bc0a7022906a7773cb8f4c36e9.pdf 